\title{
Condições de produção de subjetividade, novas fronteiras, novos Sonhos ${ }^{173}$
}

\section{Bernardo Tanis 174}

A Silvia nos aportou uma breve mas rigorosa apresentação de como após a II Guerra Mundial o consenso das nações principalmente europeias buscou superar os nacionalismos e populismos visando o sonho, a construção de um mundo sem fronteiras. Vimos momentos de otimismo ao lado do caminho sinistro do retorno dos movimentos populista de direita, a emergência dos discursos do ódio da intolerância, do racismo, das logicas binárias.

Mobilizado pelo seu texto, pelo título da mesa "Um mundo sem fronteiras: o sonho acabou?" e pelo estímulo que nos foi encaminhado, resolvi fazer um mini roteiro investigativo que talvez possa jogar certa luz para nos analistas e pessoas interessadas nos destinos da subjetividade no atual contexto social e histórico. Lançar algumas ideias em torno da produção de subjetividade com esta conjuntura econômico-política. Com a humildade de quem não é um cientista político.

Isso pressupõe que nos indaguemos sobre os diferentes espaços nos quais os sonhos são produzidos. E como o sonho, para além da realização do desejo infantil recalcado, é também uma usina de produção de elementos para simbolização (simbolização que é um produto cultural e histórico), somos conduzido a refletir sobre às condições de produção da subjetividade. Dizer que a simbolização é um produto cultural e histórico é uma colocação grávida de consequências que não se reduz, como veremos, a uma produção individual o dual. Envolve uma dimensão terceira da linguagem e do contexto. Assim, pensar psicanaliticamente os nossos sonhos e a construção de um futuro possível, terá que contemplar a complexidade e realidade do mundo em que vivemos.

Para tornar menos abstrata a nossa conversa, gostaria de lhes apresentar o trailer do filme Rede de Ódio, filme polonês do diretor Jan Komasa. O jovem protagonista que vocês verão trabalha numa agência clandestina de conteúdos

173 Trabalho apresentado na mesa de encerramento "Um mundo sem fronteiras: o sonho acabou?" do II Simpósio Bienal SBPSP “Fronteiras da Psicanálise: a clínica em movimento”, no dia 29 de agosto de 2020.

174 Membro efetivo e presidente da SBPSP, docente do Instituto de Psicanálise Durval Marcondes da SBPSP, Doutor pelo Núcleo de Psicanálise da PUC-SP. 
veiculados via internet, que visa danificar as imagens de pessoas públicas através de fake news . Desde o momento em que é expulso da Faculdade de direto por plágio, Tomasz parece ir ganhando força: quanto mais é humilhado mais forte se torna. Há algo do Coringa nesta personagem assustadora e patética.

No mundo criado pelo diretor Jan Komasa o protagonistas aparece inicialmente como refém do passado, e molda sua vida atual com base no que já perdera ou nunca tivera. Sem lugar no mundo, parece ter se encontrado e se alimenta da energia do ódio e intolerância que reside na internet. É ali não apenas faz sua morada, mas também fonte de sua potência destrutiva.

Diz a crítica: "Seu comportamento narcisista com traços de sociopatia é o que move a trama de Rede de Ódio, especialmente quando é possível observar uma mudança de foco a partir do momento em que ele é rejeitado pela melhor amiga de infância. Se no início do filme Tomasz é um mero estudante de Direito que acabou de ser expulso da faculdade, ao chegarmos no trágico desfecho já pudemos acompanhar o personagem perder todo e qualquer tipo de limite."

Trabalhando nas sombras e evitando deixar rastros, Tomasz vê na solidão uma amiga e inimiga; pois, ao mesmo tempo em que conquista a atenção e o carinho que necessita, ele se depara com um vácuo emocional que só foi capaz de existir graças às próprias ações - ou àquelas que induziu a outros.

Silvana Rea nos indaga nos seu estímulo para nossa conversa, se "as utopias falham ao se deparar com as pulsões humanas, na linha abordada por Freud em seu "Mal estar na civilização" (1930), ou com questões narcísicas (Freud, 1914)? As mudanças sociais inclusivas teriam gerado uma espécie de ressentimento em partes da população mundial?”. Cita a tese de Bauman (2017), para quem "a força do social não se volta mais para o alcance de um objetivo comum, derrocando a noção de progresso como um bem que deve ser partilhado e sonho humano de viver em comunidades sem fronteiras, de iguais. Em seu lugar, há a busca pelo prazer e a pela melhoria da posição individual".

Este presente distópico, no qual o mal parece triunfar, vem sendo objeto de múltiplas interpretações, que procuram compreender os discursos do ódio e a ascensão do populismo de direita como a Silvia nos mostrou. Vários livros prenunciam o fracasso das democracias. Se há décadas a pós modernidade anunciava o fim das narrativas, hoje celebram-se a criação de falsas narrativas sobre demanda para conseguir seduzir grandes contingentes populacionais, 
iludindo e oferecendo a miragem de saídas mágicas para a falta de esperança, a miséria econômica e social ou o vazio existencial.

É próprio da Psicanálise não recuar no exercício que nos permita jogar alguma luz nas obscuras forças que parecem tomar conta da nossa existência, e comandar nações. Talvez os modelos teórico clínicos que manejamos sejam suficientes para este exercício. Penso que eles podem ser tomados como ponto de partida fundamental, mas seria necessário algumas reformulações ou acréscimos às nossas teorias consagradas para darmos conta das profundas transformações do capitalismo tardio e das mudanças culturais e na subjetividade.

Vamos tornar isto mais concreto. Diz o crítico sobre o Thomas: "Seu comportamento narcisista com traços de sociopatia é o que move a trama de Rede de Ódio". Poderia ser a fala de um analista bem formado e experiente, que reconhecendo a humilhação e fragilidade narcísica, entende o paciente movido pelo ressentimento, buscando uma afirmação narcísica que recusa uma ética de compromisso com o semelhante. Isso daria um belo trabalho para uma reunião científica. Isso em princípio não seria falso, mas será que dá conta daquilo que o filme nos propõe? O que o real nos demanda?

Acho que é insuficiente, que devemos dar um passo para além do intrapsíquico ou das falhas dos objetos primários, território este que a psicanálise contemporânea mapeou com brilhantismo com Bion, Winnicott, Green e tantos outros.

Para este passo teremos que atravessar fronteiras e nos aventurarmos em territórios menos conhecidos. Acredito ser este o legado freudiano. Duas psicanalistas Silvia Bleichmar e Janine Puget me inspiram e acompanham nessa travessia.

Vejamos como Silvia Bleichmar além de criativa e brilhante analista de crianças, trabalhou em situações de traumas sociais e catástrofes, com vítimas do terremoto do México e do terrorismo de estado e atentados. Essas experiências alargaram sua compreensão sobre o trauma. A sua percepção a leva a formular a seguinte hipótese: "os efeitos desestruturantes, os grandes traumatismos, se bem incidem sobre as estruturas anteriores, não são apenas desencadeantes mas constitutivos. Vale dizer que desde sua perspectiva recupera o elemento atual". E gostaria que vocês dessem atenção a esta palavra: o atual! 
Classicamente o que desencadeia o traumatismo já está no sujeito. Para Bleichmar os efeitos desestruturantes, os grandes traumatismos, ainda que incidam sobre as estruturas anteriores, não são apenas desencadeantes. São constitutivos. O estupor, a paralisia convocam toda a economia libidinal que estaria destinada a conter os elementos desgarrados do psiquismo. No início não há sintomas, apenas no segundo tempo quando há uma recomposição psíquica. Encontramos no início comoção, desorganização, apatia, e só posteriormente aparece a reorganização psíquica.

Neste sentido a estrutura não volta ao ponto de partida. Ela se recompõe em um nível diferente, as vezes capaz de criar soluções simbólicas, mas muitas outras gera cicatrizes, queloides, marcas indeléveis condenadas a compulsão a repetição ou a soluções não simbólicas. É o que está em pauta para catástrofes social, terrorismos de estado, pandemia: a forma o discurso e os atos pelos quais a sociedade articula as redes simbólicas de reconhecimento das vítimas.

Esta formulação tem implicações de maior alcance, pois extrapola a conjuntura inerente aos grandes traumatismos se a tomamos como modelo paradigmático da constituição da subjetividade. Pois se a contenção e elaboração do traumático não diz respeito a processos de subjetivação apenas intrapsíquicos e envolve o campo intersubjetivo e social, mutatis mutandis as mudanças presentes na transformação do sofrimento psíquico em formações sintomáticas guarda alguma relação com as modalidades pelas quais a cultura captura ou não o mal-estar. A patologia não é determinada pelo inconsciente, mas pela relação do inconsciente com os modos com os quais o Eu se estrutura, vinculado a ideologia da sociedade de pertinência. As pulões de vida e de morte não são forças autônomas a comandar o destino da humanidade, será a cultura que poderá ou não favorecer certos caminhos e diferentes contextos históricos.

Retomando o nosso título o sonho acabou, psicanaliticamente temos que nos preguntar sobre as condições atuais do sonhar, seja no campo individual seja no campo coletivo. Quando a ética da alteridade se corrompe no atual, quando o outro é reduzido a condição de verme que deve ser eliminado o tecido social se esgarça e o caminho da sua recomposição torna-se uma tarefa hercúlea.

Se vocês tiverem paciência podemos avançar um pouco a perspectiva de uma clínica e teorias psicanalíticas que possam incluir no seu bojo a produção social da subjetividade. Lipovetsky falara em "era do vazio", conceituação tal vez 
válida para uma Europa, saturada do desenvolvimento capitalista. Mas e nós no Brasil, na América Latina? Mais do que saturação, vivemos hoje o desalento, sentimos que não estamos fazendo o dever de casa para mitigar a miséria a violência social a discriminação a opressão. Território fecundo para o fortalecimento das fantasias transcendentes, o fundamentalismo aparece ligado a valores que possibilitam e sustentam estas fantasias. Autoritarismo populista, o nacionalismo pueril captura os mais desavisados com migalhas de esperança.

Bleichmar dirá que "a patologia não é determinada pelo inconsciente, mas da relação do inconsciente com os modos com os quais o Eu se estrutura, vinculado a ideologia da sociedade de pertinência”. Assim Thomas, não pode ser avaliado apenas como um caso de uma patologia individual; seu modo de subjetivação ganha as formas que o social - oferece para tramitar o mal-estar. O que coloca limite à violência, à impunidade. Qual o frei perante uma violência, que como diz Puget: "visa arrasar, devastar ou expulsar do corpo social uma parte do mesmo". Uma violência que se transforma em espetáculo, mas que também age invisivelmente.

A confiança no futuro só poderá advir se produção de subjetividade puder contemplar o respeito por si mesmo e pelo outro. Esse reconhecimento da alteridade e do direito a diferença pertence ao campo da ética. Ética diz respeito a presença do outro, não apenas às formas históricas de legislar. Nas atuais múltiplas formas de violência predominam os processos de dessubjetivação e impunidade. A vítima deixa de ser visível é abolida a noção universal do semelhante.

A psicanálise como crítica da cultura e como pratica clínica dá voz à alteridade, ao desacordo, à multiplicidade. Procura se afastar das opiniões categóricas e fomentar o diálogo mesmo sabendo que há diferenças irredutíveis. Nós, analistas, habitamos este mundo onde reinam as polaridades, amor-ódio, certo-errado, bem-mal, amigo inimigo. Nossas vidas e instituições, não estão livres de pensamentos autoritários de rumores que visam destruir o outro, de inveja e ressentimentos. Cuidar de mal-estar interno, olhar para nós pode ser a tarefa coletiva que nos ajude a não sucumbir a uma produção de subjetividade de muros e fronteiras rígidas intransponíveis. 